\title{
Editorial: If database marketing was so good, why is CRM so bad?
}

Things were much better before we started using the term customer relationship management (CRM). Database marketing was great and had a good future. Over 80 per cent of CRM projects fail in Europe. Is this due to unrealistic expectations or is something more fundamentally wrong? Is CRM yet another bubble like the stock market or Internet dot.coms?

Companies have already embraced database marketing and now know who are their best customers. Businesses are developing CRM capabilities so that they can give the right offer, to the right person, at the right time and through the right channel. This can be much more complicated than database marketing.

Today it is a thousand times cheaper to hold a customer's details on a computer than it was 20 years ago. Media and markets are fragmenting. Marketing budgets continue to be squeezed. The ability for advertisers to identify key customers and prospects is no longer a 'nice to have' but a necessity. This is achieved through the use of databases for segmentation and targeting.

Mass production and mass media enabled mass marketing. Then the computer and the marketing database facilitated database marketing. CRM and the Internet are making one-to-one marketing a reality.

Companies are focusing more on customer retention and loyalty than customer acquisition because it is more profitable to keep customers than to get them. Advertising campaigns are moving from single channel to multichannel, such as television to support a direct mail campaign. This multichannel complexity is exacerbated by campaigns moving from being quarterly to continuous or even real time using trigger data such as a birth or retirement. There has been a corresponding shift from demographic or recency, frequency and money (RFM) segmentation to behavioural or transactional segmentation based on more detailed customer activity or life events.

The real-time nature of CRM creates an issue. A traditional marketing database has an update cycle. If a customer buys a product in the morning and someone in a call centre tries to sell that customer the same product that afternoon it does not reflect well on the company. This can be worked around through stop files but this is not really satisfactory. Often the best time to sell to a customer is when they make contact with the company. This results in a pull strategy rather than a push strategy. These incoming customer contacts need to trigger real-time responses, for example while the call-centre operator is on the phone with the customer. Call centres are a good example of technology being ahead of its application.

Winston Churchill said that someone who does not understand history is forced to relive it. One-to-one marketing has followed a path that is analogous to business process re-engineering so it is worth comparing the two to understand better how CRM is most likely to develop in the future. Business process re-engineering (BPR) emerged in the 1990s. It involves 
analysing a company's core processes and reassembling them in a more efficient way without functional divides. This requirement led to the emergence of enterprise resource planning (ERP) software from companies such as SAP, which integrate back-office systems such as production, distribution, contract and order management, as well as financial and human resource management. In a similar way, CRM requires the integration of many different front-office customer facing functions from the call centre and sales force to the marketing database. Areas not traditionally associated with marketing, such as the complaints department, become important. BPR and ERP led to many companies restructuring in the early 1990s better to align their company structure with their business processes. Likewise, CRM requires better alignment of a company's structure away from products and functional silos towards customers. Company restructuring was probably the biggest barrier to BPR. Too many companies have bought technical solutions and avoided more difficult cultural and restructuring issues to make the business more customercentric. Few companies embarked on BPR and ERP without first mapping out their core processes. Many companies, however, have started CRM projects without a customer segmentation strategy or plan for what they might do with a single customer view.

A barrier to one-to-one marketing is the administrative complexity required for complete customisation at the individual customer level. The marketing department is responsible for the administration of marketing programmes. A key issue is how much administrative complexity a marketing manager can handle. A reasonable level would be managing, say, 40 to 50 different programmes. A segmentation strategy that classifies customers into 40 to 50 different groups starts to make sense. Segmentation groups consumers with similar requirements giving the marketing manager a manageable number of specific strategies and marketing programmes. Companies can use segmentation strategies to make one-to-one marketing more manageable. Many companies purchased campaign management tools to enable the marketing department to run more campaigns rather than developing a segmentation strategy. A segmentation strategy is successful when from the boardroom to the cash register or to the call centre employees talk about how they are moving customers from one segment to another.

Computer costs halve every 18 months, but companies' IT expenditure remains relatively constant. Companies must therefore be processing twice as many data every 18 months. As a result marketing departments are becoming data rich, but information poor. Ninety per cent of businesses suffer from information overload according to Gartner. Companies need a strategy to help everyone in the organisation sort and understand those data before making this worse with CRM. Similarly, one can not manage what one can not measure and too few companies measure individual customer lifetime value before starting CRM projects.

Gartner forecasts that CRM services revenue will increase 15 per cent in 2002 . The market is forecast to nearly double and reach US $\$ 47$ bn by 2006 . Companies are turning from operational and tactical CRM technology-led initiatives to CRM analytics and business intelligence, and this may be why the future looks brighter for CRM than the present.

MARK PATRON Database Marketing Consultant, and Editorial Board Member 